\title{
A CONSOLIDAÇÃO DA MARCA ZONA SUL NO SEGMENTO DE SUPERMERCADOS:
}

\section{UM ESTUDO DE CASO}

\section{Carlos José Guimarães Cova}

\section{Erick Jacobina Ladewig de Araújo}

\section{RESUMO}

0 presente trabalho se propõe a apresentar os conceitos relativos à consolidação da marca, ou Brand, como elemento de diferenciação da concorrência e fundamento da estratégia corporativa. Preliminarmente apresentaremos os conceitos atinentes à relação do marketing com a estratégia de marca, bem como o processo decisório envolvendo o Brand. Em seguida faremos uma exposição das principais ações que devem ser empreendidas para o estabelecimento do relacionamento com os clientes. Por fim, apresentamos o estudo de caso do Supermercado Zona Sul, como exemplo de sucesso da aplicação.

\begin{abstract}
This study aims to present the concepts related to the consolidation. Brand as an element of competition and differentiation of the foundation of corporate strategy. First present the concepts related to relationship marketing strategy for the brand, and the process involving the Brand. Then we will explain the main actions to be undertaken to establish the relationship with customers. Finally, we present the case study of Supermercado Zona Sul as an example of successful application of these doctrinal aspects.
\end{abstract}




\section{APRESENTAÇÃO}

Os produtos, assim como as pessoas, têm personalidade. Eles podem ficar conhecidos ou desaparecer dos mercados. A maioria das pessoas já ouviu falar da Xerox, da Gillette, da CocaCola, da Nike, ou Mc Donald's. Mas poucos se dão conta de que estas palavras são apenas nomes e não produtos propriamente ditos. Porém, quando alguém precisa de uma cópia de um documento, provavelmente dirá: "Preciso de uma xerox". Ou ainda, quando uma pessoa pensa em um sanduíche, logo vem em sua mente o Mc Donald's. Essas associações acontecem porque alguns nomes criam um reconhecimento, ou seja, uma identidade que se transforma em um produto na cabeça do consumidor.

Essa identidade é criada através de um conjunto de valores que a marca deseja transmitir, fazendo com que se estabeleça um vínculo entre esses valores e as características da personalidade do público alvo. Um bom exemplo para ilustrar este fato é a marca Marlboro, que através do seu tradicional cow-boy passa ao seu público alvo alguns valores, tais como liberdade e masculinidade, de tal forma que as pessoas que possuem estas características em sua personalidade sentem o desejo de fazer parte do contexto em que ele se insere.

De acordo com Kotler (2001, p 525), a marca pode ser traduzida por um nome, um termo, um símbolo, um desenho ou mesmo uma combinação de todos esses elementos, que deve identificar os bens ou serviços de uma empresa e diferenciá-los dos seus equivalentes comercializados pela concorrência. Entrementes, atualmente o ato de consolidar a marca no mercado e ter um produto bem aceito somente pelo consumidor, não é suficiente para atender às necessidades estratégicas das organizações. No ambiente altamente competitivo no qual as empresas estão inseridas, é necessário investir na melhoria dos serviços prestados ao cliente e na capacidade de agregar valor como um todo.

As marcas desempenharam durante o último século um papel crucial para as maiores organizações em todo o mundo. Empresas como a Procter \& Gamble, Gillette ou Levi's, construíram autênticos impérios com base na força e valor dos seus nomes de marca. Hoje as marcas são reconhecidas não só como meros nomes, mas também como representações em grande escala das empresas.

$\mathrm{O}$ ato de dar nome a um produto ou serviço evoluiu muito nos últimos tempos. $\mathrm{O}$ que antes era uma tarefa informal é agora um dos aspectos mais importantes no desenvolvimento de novos produtos. Quando pensamos em refrigerante o nome que nos ocorre é, provavelmente, Coca Cola. Provavelmente, quando se pensa num tênis, a idéia que eventualmente surja seja o da marca Nike. Algumas marcas tornaram-se tão conhecidas que substituíram o produto em si. Muitas destas marcas surgiram a partir dos nomes dos seus inventores ou produtores, outras estão relacionadas com a funcionalidade do produto, como a Xerox (de origem grega, composição de palavras que exprime a idéia de seco).

Em marketing, as definições de marca têm sido derivadas do conceito jurídico: a marca jurídica é, antes de mais, um sinal distintivo de produtos ou serviços. A progressiva consciência da missão estratégica das marcas alargou o conceito: hoje podemos dizer que é a marca, e não mais o produto, a unidade estruturante da oferta das organizações.

Numa abordagem semiótica da marca, esta é assumida na sua tripla condição: de sinal, de objeto a que o sinal se refere, e de interpretações a que o sinal dá origem. A marca surge assim como um sinal ou conjunto de sinais de identidade, distintivos de uma missão e das 
respectivas ações de marketing oferecidas por uma organização, com o objetivo de obter uma imagem junto aos públicos aos quais se dirige. A marca torna-se, dessa forma, um instrumento potencializador de valor. As fontes do valor da marca são precisamente os sinais de identidade e as ações de marketing que a marca dirige aos públicos que elege como alvos, bem como, e em última instância, o patrimônio de notoriedade e de associações, atributos, benefícios e atitudes, conquistado junto desses mesmos públicos.

A marca não é um conceito fácil de definir e caracterizar. Na sua definição e análise imbricamse várias disciplinas, em especial aquelas que a utilizam e regulam mais diretamente, que são o Direito Comercial e a Gestão de Marketing.

As marcas devem ter um projeto de evolução. Os verdadeiros donos das marcas são os clientes e os consumidores. Portanto, para entender como essa evolução deve ser operada, é fundamental entender como o processo de expansão das marcas atua na mente dos agentes consumidores. Muitas questões ficam por ser respondidas nesse processo, mas o desafio mais premente para os gestores consiste em antecipar quais as tendências mercadológicas que ajudarão a gerar negócios com a marca já existente. Há a percepção de que a marca deve ser uma verdadeira chave para gerar retornos substanciais sobre os investimentos realizados.

Atualmente, é possível verificar que as pessoas travam contato com as marcas nas mais diversas situações: online, nas suas compras no varejo, por meio de representantes de vendas, em embalagens, por intermédio de múltiplas formas de mídia, dispostas em aviões, ônibus, trens e até nos de caminhões de transporte de cargas. Em virtude dessas múltiplas formas de comunicação de mensagens, a adoção de um processo integrado e estratégico de marketing buscará garantir uma mensagem eficiente e consistente em qualquer ponto de contato com clientes atuais e potenciais.

O estudo da marca busca identificar, através de entrevistas junto ao público alvo, a identidade entre os estilos, caracterizada pela relação entre a marca e o consumidor, ou seja, procura associar a essência do produto à emoção que existe no imaginário coletivo, pois as marcas evocam sentimentos e ligações que muitas vezes nem mesmo os próprios consumidores entendem o porquê daquela opção de compra, concluindo assim que os produtos hoje em dia estão se tornando commodities, cada vez mais parecidos, com a mesma qualidade e preço.

Portanto, a saída para obter um diferencial competitivo é a imagem que a marca passa aos consumidores e como estes a percebem. 0 presente trabalho tem como tema a consolidação de uma marca no competitivo mercado varejista de alimentos. Trataremos de uma empresa do ramo de supermercados, a rede Zona Sul que, ao invés de acompanhar os gigantes como Pão de Açúcar, Carrefour, Guanabara e Mundial na guerra desgastante de preços, procurou um caminho diferente, tendo como foco qualidade no atendimento, serviços e produtos diferenciados.

Para especialistas no assunto, a marca Zona Sul hoje no Rio de Janeiro é vista como uma rede de supermercados que, embora posicione seus preços em faixas um pouco acima dos preços praticados pelos seus concorrentes, oferece com muita competência serviços diferenciados, com foco em seu público igualmente diferenciado.

Suas 30 lojas localizadas nos famosos bairros de Botafogo, Flamengo, Urca, Copacabana, Leblon, Ipanema e São Conrado, e também na Barra da Tijuca e Recreio, corroboram com o já conhecido glamour dos mesmos. Se estivermos nestes bairros e necessitarmos de qualidade no atendimento por parte de funcionários que, habitualmente, nas outras empresas do ramo, 
deixam a desejar, podemos nos dirigir para um Supermercado Zona Sul, pois lá vamos encontrar produtos e serviços diferenciados/sofisticados e raramente encontrados, além de máxima higiene e apresentação. Analisaremos estes fatos para tentar responder a seguinte questão: o trabalho conjunto das áreas de marketing e comercial é capaz de posicionar uma marca, mesmo num ramo extremamente competitivo como é o caso do setor de supermercados, gerando rentabilidade para o negócio?

A suposição que anima este trabalho é de que, se existe um público diferenciado e pouco explorado pelas principais organizações supermercadistas, a capacidade de tratar este segmento de mercado de forma profissional, observando as suas necessidades, é possível consolidar uma marca, mesmo num ambiente de mercado competitivo, gerando uma boa rentabilidade. Trata-se de uma pesquisa exploratória, devido ao pouco conhecimento e uso de processos mercadológicos de marcas consagradas no segmento de supermercados da cidade do Rio de Janeiro.

\section{ASPECTOS DE MARKETING E ESTRATÉGIAS DE MARCA}

0 marketing é baseado no princípio de troca e facilita esse processo desempenhando uma variedade de atividades. Como um processo organizacional, o marketing desenvolve um composto que contempla decisões de produto, distribuição, promoção e fixação de preços, trabalhados e coordenados especificamente para satisfazer as necessidades dos mercados alvo pretendidos. Os elementos do composto de marketing são controláveis e ajudam as empresas a desenvolver estratégias de posicionamento que diferenciam os seus produtos das ofertas concorrentes. Uma vez que os negócios não acontecem no vácuo, as firmas bem sucedidas modificam regularmente as suas decisões de comportamento de marketing para adaptarem-se às mudanças nos ambientes interno e externo.

Por sua vez, as marcas estão associadas ao ato da venda praticamente desde os seus primórdios. Entretanto, só há alguns anos começamos a reconhecer as marcas e a criação de marcas como ingredientes vitais e necessários ao sucesso de qualquer empresa e mercado em geral.

O termo marca, de Brand, vêm da antiga palavra norueguesa que significa to burn, verbo queimar. Este termo foi designado para significar o fabricante ou o proprietário de algum item ou produto. Por isso, fala-se no termo 'marcar' gado, cavalos, etc.".

A Associação de Marketing Americana, define uma marca como "Um nome, termo, sinal, símbolo ou qualquer outra característica que identifique um bem ou serviço do vendedor, em distinção a outros dos demais vendedores".

De acordo com Kotler, a marca é um nome, termo, símbolo, desenho ou a combinação de todos esses elementos, ele ainda salienta que, as melhores marcas trazem consigo uma garantia de qualidade. A marca é um símbolo muito mais complexo em virtude de trazer até seis níveis de significado. Os atributos que a marca traz à mente do consumidor são: o valor da empresa que a marca representa; a cultura que a marca pode representar; a marca pode projetar certa personalidade; além de sugerir o tipo de consumidor que compra e/ou usa o produto.

A marca é um nome, um sinal, um símbolo, ou design, ou uma combinação de tudo isso, com o objetivo de identificar produtos ou serviços de um vendedor ou grupo de vendedores e diferenciá-los de seus concorrentes. A marca individual é única para um produto particular, que pode incluir múltiplos sabores ou estilos e múltiplos tamanhos, e assim por diante. A 
marca de família é aplicada a uma linha inteira de diferentes produtos. A marca de fabricante pode ser regional ou nacional, dependendo do escopo de cobertura de distribuição da marca.

A marca de revendedor (ou etiqueta privada, ou marca da casa) é controlada por propriedade de uso por um distribuidor, uma instituição varejista, atacadista ou um distribuidor industrial. A propriedade e o controle de uma marca coexistem com a atitude e controle da estratégia de marketing para uma marca.

Todas as pessoas têm um nome, e são por estes nomes que são identificadas. Com produtos e empresas não é diferente. Normalmente, as empresas escolhem nomes de marcas por meio de uma lista de possíveis nomes e testam-nos com os consumidores. Algumas contratam empresas especializadas para a escolha. Entretanto, a decisão seja com ou sem ajuda de um profissional são as mesmas. Os fabricantes e as empresas de serviços que estabelecem marcas para seus produtos devem escolher quais nomes de marca usar. Conforme ensina Kotler (2000, p 469), há quatro estratégias possíveis.

1o - Nomes Individuais: A empresa não associa sua reputação à do produto. É um nome qualquer. Se o produto fracassa ou parece ter baixa qualidade, o nome e a imagem da empresa não são afetados.

2o - Nomes de família abrangentes: É o nome do fabricante. Não há necessidade de gastos com pesquisas de "nome" nem de gastos para criar o reconhecimento do nome da marca. Exemplo: Parmalat.

3o - Nomes de famílias separados: Quando uma empresa fabrica produtos bem diferentes, não é desejável usar o nome de família abrangente, por isso cria-se outro. É o caso da Nestlé S.A. que tem um segmento de comidas para gatos, mas com nome diferente: Purina S.A.

$4^{\mathrm{o}}$ - Nome comercial da empresa combinada com diferentes nomes de produtos: Algumas empresas associam seu nome com o nome de marca de cada produto. 0 nome da empresa legitima o produto e o nome individual o identifica. Exemplo: Kellogg's Corn Flakes.

Uma vez escolhida a estratégia de nome de marca, a empresa deve escolher um nome de marca específico, seja um nome relacionado à pessoa, a uma localidade, ou até mesmo outro nome qualquer. Levando sempre em consideração que o nome escolhido deve ser de fácil pronúncia, sugerir algo de bom a respeito dos benefícios e qualidade do produto, um nome de fácil identificação com o produto, de preferência com poucas sílabas e com um detalhe importante se o produto for internacionalizado: não deve apresentar significados negativos em outros países.

Tais observações teóricas, uma vez que, na prática, existe apenas um número limitado de sugestões que atendem à política de portfólio de produtos e de marcas da empresa. Quando o nome do produto não é inteligível, ele pode estimular um consumo ou compra inadequada. Por essa razão, muitas vezes é importante que a marca se apresente aos olhos do consumidor como uma mensagem que contenha informações.

Podemos observar que a adoção da marca do fabricante em adição à marca do produto é uma forma de avalizar o conteúdo. Por exemplo: a água mineral Minalba é da Nestlé. A representação associada do nome do fabricante a uma marca-fantasia ajuda a promover o produto até que ele atinja a maioridade comercial. A escolha de uma marca muitas vezes é associada às idéias que permitem uma identificação rápida do produto, ou seja, o que é e para 
que é utilizado. Por exemplo, o Chá Mate Leão.

Algumas marcas tentam indiciar as propriedades do produto. É o caso da Sadia (produtos higiênicos e sadios). Outras vezes, a marca indica o objeto do produto, como é ocaso da marca Memorex (para a memória). Outras marcas exprimem convite ou sedução ao consumo, tal como o açúcar Doce Vida. Há ainda as marcas indicam distinção e decência, como no caso do uísque House of Lords.

O fato é que, se a marca não faz a venda, ajuda e muito a vender. À medida que uma marca ajuda a distinguir e notabilizar um produto, mais depressa ele é vendido. A indicação clara das propriedades e os efeitos do produto também é um importante fator promocional. E a retenção do nome na memória do consumidor é fator decisivo no momento da escolha do produto. Com efeito, uma das características mais importantes de uma marca é a fácil memorização. As siglas, os símbolos, as cores e os logotipos da marcas (LOGO-MARCAS) são de grande influência no grau de atenção que é concedido ao produto pelos observadores. A estrela da Mercedes-Benz é conhecida mundialmente. As cores das sopas Maggi da Nestlé são inconfundíveis. A questão central se dá em como usar a criatividade no nome da marca e nas suas formas de representação gráfica para que ela estimule o consumidor a comprar.

\section{A DECISÃO SOBRE A ESTRATÉGIA DE MARCA}

A marca é um item extremamente importante na estratégia do produto. Estabelecer uma marca consome tempo, dinheiro e ao mesmo tempo em que pode promover um produto, pode destruí-lo.

De acordo com Gilson Nunes ${ }^{1}$, editor da Revista The Brander, as marcas podem representar até $95 \%$ do valor de uma empresa e possuem o poder de influenciar a demanda do consumidor, parceiros, sociedade, canais de vendas e distribuição, lealdade dos colaboradores, condições e termos de fornecimento, interesse dos investidores, de tal forma a transformar a performance do negócio, aumentando seu resultado financeiro.

Com relação à marca, KOTLER (2000, p. 525) afirma: "uma empresa pode ter cinco escolhas em termos de estratégia de marca. Pode promover extensões de linhas, extensões de marcas, podem lançar multimarcas, novas marcas e também marcas combinadas. Além de claro, decidir primeiramente se deve criar ou não uma marca".

Estender sua linha nada mais é do que lançar alguns itens a mais na mesma categoria de produtos sob o mesmo nome de marca. Isto significa que a empresa pode lançar novos sabores, formas, cores, para a mesma linha do produto. Um caso bem típico é a Coca-Cola, que disponibiliza o mesmo produto, Coca-Cola, em latas de alumínio, em garrafas, tanto de 1 litro, quanto de $300 \mathrm{ml}$ e nas versões Coca Diet, Coca Light, Coca Zero etc. A extensão de linha tem muito mais chance de sucesso do que criar novos produtos. Nas extensões de marca, como o próprio nome já diz, a empresa usa o nome de marca já existente para lançar novos produtos em outras categorias.

Por sua vez, as Multimarcas, que não são muito usadas, permitem que a empresa detenha mais espaço na prateleira dos distribuidores e proteja sua marca dominante. É o caso do Sabão em pó Omo, que é o carro chefe da Gessy Lever, ao mesmo tempo em que a Gessy Lever tem o sabão Minerva e o Brilhante. Ou seja, a empresa utilizou-se de multimarcas para proteger o seu sabão em pó líder de mercado. 0 maior risco de lançar marcas adicionais na mesma categoria de produtos é o fato de que todas devem apenas obter uma pequena 
participação de mercado e talvez, nenhuma seja rentável.

De acordo com Aaker et Alii (2007, p.24), o desenvolvimento de uma identidade de marca depende da ampla compreensão acerca dos clientes, dos concorrentes e da estratégia de negócios da empresa. Como são os clientes que impulsionam, com suas decisões de compra, o valor de uma marca, uma estratégia de marca deve se apoiar no conhecimento das motivações dos clientes.

\section{O BRANDY EQUITY - PATRIMÔNIO DA MARCA}

Desenvolver enfoques para atribuir valor à marca é uma ação de grande importância para as empresas, porque as marcas, ao mesmo tempo em que são compradas e vendidas, recebem investimentos para incrementar o seu potencial de direcionador de vendas.

Para calcular o valor de uma marca, cinco enfoques são levados em conta. Conforme ensina AAKER (1998, p 23), são eles: o Premium price que a marca pode suportar; o impacto do nome na preferência do consumidor; o valor da substituição da marca; o preço de ação; e por último, focalizar o poder de ganho de uma marca.

0 Conhecimento pela marca, a qualidade percebida pelo cliente por ela representada, as associações e a lealdade à marca, têm potencial para identificar o posicionamento do Premium price, bem como uma observação dos níveis de preço do mercado praticados para as demais marcas ou até mesmo, por uma pesquisa junto ao consumidor verificando o quanto ele pagaria por vários atributos e características de um produto.

Quando os produtos e/ou serviços têm preços muito similares, a melhor maneira de se quantificar o Brand equity, ou patrimônio da marca, é considerar o nome da marca escolhido pelo consumidor. Assim, a marca é medida pela preferência, atitude ou intenção de compra e é de grande importância saber quanto o nome da marca contribui para a participação no mercado e a lealdade a ela dirigida.

1 Publicado em The Brande® - Marcas Brasil, Edição 12009

o Custo de Substituição da marca diz respeito ao confronto de quanto a empresa deveria desembolsar para lançar um novo produto (sabendo das chances de sucesso) em face da opção de investir esta mesma quantidade na marca já estabelecida no mercado e reforça a sua imagem perante $\mathrm{o}$ consumidor.

Segundo a definição de AAKER (1998, p 16), o Brand equity compreende um conjunto de ativos e passivos ligados à marca com seu respectivo nome e símbolo. Em outras palavras, este patrimônio relaciona-se ao grau de reconhecimento da marca, à lealdade a ela, à qualidade percebida da marca, a fortes associações emocionais e mentais e a outras propriedades como patentes marcas comerciais e relacionamento nos canais.

O Brand equity proporciona valor para o cliente na mesma proporção que agrega valor para a empresa. Os ativos do Brand equity afetam o consumidor na decisão de compra e, na medida em que adicionam valor para o consumidor, têm o potencial de acrescentar valor para a empresa na geração marginal de fluxo de caixa. A empresa, conseqüentemente, poderá investir em programas para atrair novos consumidores ou reconquistar os antigos; aumentar 
a extensão da marca; obter novo canal de distribuição etc., fazendo com que todos os ativos do Brand equity proporcionem uma vantagem competitiva perante seus concorrentes.

\section{O CONHECIMENTO DE MARCA}

AAKER (1998, p 59), afirma que "o conhecimento da marca é a capacidade que um comprador potencial tem de reconhecer ou de se recordar de uma marca como integrante de uma certa categoria de produtos".

O conhecimento da marca envolve um intervalo que varia desde o simples reconhecimento da marca até a crença de que ela é a única nesta classe de produtos. Numa espécie de etapas, o nível mais baixo é o reconhecimento da marca, quando o comprador escolhe a marca no ponto de venda. Não há vínculo de relacionamento. Em seguida, o próximo nível é a lembrança da marca, onde a lembrança é espontânea e não necessita de estímulos para ser lembrada. E por último, a primeira marca que vem à mente do consumidor, sem estímulos, se enquadra na classificação de Top of Mind. De certa forma, ela está numa posição frente às outras marcas na lembrança das pessoas, mesmo havendo uma outra bem próxima a ela.

É importante salientar que o reconhecimento da marca (o primeiro nível) é o primeiro passo na tarefa de uma eficiente comunicação. 0 reconhecimento da marca é a chave para o início de uma construção de uma marca duradoura.

Para atingir o conhecimento de uma marca é preciso cumprir duas tarefas: a primeira é ganhar a identidade do nome da marca e a outra é fazer um link à classe do produto. Se a marca é nova, ambas as tarefas são necessárias. Caso contrário, onde um destes contextos já foi realizado, a questão torna-se outra e o melhor caminho para o conhecimento ser atingido, mantido ou melhorado, depende de todo um contexto.

\section{A IMAGEM DE MARCA}

De acordo com AAKER (1996, p 80), “a imagem da marca pode ser definida como o conjunto de atributos e associações que os consumidores reconhecem e conectam com o nome da marca". Essa imagem que os consumidores têm em relação às mais variadas marcas é obtida através de atributos, sentimentos e percepções que cada pessoa conecta a uma marca qualquer.

As associações feitas pela imagem da marca tanto podem ser tangíveis como intangíveis. Isso quer dizer que, ao mesmo tempo em que são relacionados atributos funcionais como preço, performance do produto, serviços e tecnologia, são atribuídos valores emocionais às marcas. Este fato, provavelmente, garante um maior reconhecimento em relação às demais marcas que não exploram esta dimensão com ênfase.

A imagem de uma marca pode ser construída por vários meios: informações veiculadas pelos meios de comunicação; informações transmitidas pela embalagem do produto; pelo uso do mesmo; por promoções nos pontos de vendas; propaganda; publicidade. Enfim, diversas são as maneiras de se construir e consolidar uma marca em um mercado, mas a mais eficiente e considerada uma ferramenta indispensável para o sucesso da mesma é a publicidade.

A penetração e a abrangência que a publicidade é capaz de atingir, são elementos fundamentais para que se possa provocar o convencimento sobre a supremacia da marca na maioria dos consumidores. 
O relacionamento do consumidor com as marcas é uma das áreas mais complexas no estudo de marketing. Atualmente se fala muito em marketing de relacionamento, ou seja, o que o marketing precisa fazer para estabelecer relacionamentos mutuamente satisfatórios de longo prazo com clientes, fornecedores e distribuidores, a fim de ganhar e reter sua preferência. Uma marca é um conceito global e único. Ela terá sucesso se os consumidores a perceberem como sendo melhor do que as marcas dos concorrentes.

\section{O MARKETING DE RELACIONAMENTO}

A primeira impressão que o cliente tem da empresa é a mais duradoura. Seja qual for a política ou o método de atendimento, é preciso estar comprometido com a qualidade e por isso é fundamental a formação adequada dos profissionais que entrarão em contato direto com os clientes, quer para promover os seus produtos e serviços, quer para responder a reclamações ou dar esclarecimentos. Uma vez que as empresas decidam colocar o cliente em primeiro lugar como estratégia para garantir seu presente e futuro, é importante cuidar para que o atendimento seja um valor manifesto no conjunto de sentimentos do cliente. Não é possível conseguir a "excelência no atendimento" se não houver um conhecimento prévio das necessidades, expectativas e ansiedades que estão apenas na mente do cliente. Isto também vale para as pessoas envolvidas na organização quanto ao atendimento ao cliente. Explorando o conhecimento que cada uma delas possui da empresa, do produto ou serviço oferecido, do mercado e dos diversos tipos de clientes que freqüentam a sua loja ou outro tipo de negócio.

A concorrência entre empresas esta cada vez mais acirrada, uma vez que vivemos em um mundo globalizado. Sob a ótica econômica, a maior conseqüência desta situação para as empresas é a competição. 0 consumidor tem mudado muito nos últimos anos, uma vez que suas exigências estão crescendo, na mesma proporção em que sua paciência está diminuindo. Isto significa que, para sobreviver, a empresa deve prestar um excelente atendimento ao cliente.

O marketing de Relacionamento consiste no uso de uma ampla gama de técnicas e processos de marketing, vendas, comunicação e cuidado com o cliente para identificar os clientes de forma individualizada e nominal, bem como criar um relacionamento entre a empresa e seus clientes (um relacionamento que se prolonga por muitas transações), ao mesmo tempo em que é capaz de administrar esse relacionamento para o benefício dos seus clientes e da empresa.

O posicionamento começa com o consumidor. Os consumidores pensam sobre os produtos e empresas comparando-os com outros produtos e empresas. 0 que realmente importa é como os possíveis clientes e os já existentes vêem uma empresa em relação às concorrentes. Os consumidores definem uma hierarquia de valores, desejos e necessidades com base em dados empíricos, opiniões, referências obtidas através de propaganda de boca a boca e experiências com produtos e serviços. Usam essas informações para tomar decisões de compra.

A liderança no mercado pode chamar a atenção de um consumidor e ser um fator importante a ser considerado por ele. Mas, hoje, existe mais de um único líder em praticamente todos os segmentos do mercado. A concorrência se intensifica nas áreas de características e preço. As empresas tentam manter a diferenciação por meio do mix de características e da marca. Nos mercados de consumo, os gastos com propaganda aumentam dramaticamente.

O marketing é definido como a ciência e arte de encontrar e manter clientes e desenvolver relacionamentos lucrativos com eles. A empresa, hoje, está transferindo sua ênfase na busca 
de novos clientes para a aprendizagem de novas formas de manter e aumentar a lucratividade dos atuais produtos e serviços. 0 desenvolvimento de um relacionamento profundo com um segmento de clientes normalmente é muito mais importante do que os números podem sugerir.

Os clientes leais e comprometidos não apenas influenciam outras pessoas, como também fornecem uma base estável de vendas.

O desejo de ajudar é a alma do trabalho de atendimento. Isto significa que o desejo de ajudar deve vir de dos escalões mais altos da empresa. É necessário o exemplo do patrão falando com os funcionários e clientes. Isto porque, a principal característica do ato de servir é a humildade.

Embora as pesquisas deixem explícito que o processo de atendimento é primordial para a sobrevivência de qualquer instituição organizacional, na prática, o que se tem visto são muitos profissionais atendendo como se estivessem fazendo um favor aos clientes. Não prestam a devida atenção e simplesmente ignoram os argumentos ou reclamações do consumidor. É preciso entender que não se faz qualquer favor ao atender com educação, atenção e respeito os compradores. Isto hoje é o mínimo que se pode esperar de um bom atendimento e, em breve, isto já não será suficiente. 0 cliente escolheu a empresa dentre tantas outras e ela não tem o direito de perdê-lo. Na realidade, o cliente é que esta fazendo um favor, ao preferir uma determinada empresa e seu atendimento.

Existem alguns vendedores que defendem a política dos preços. 0 preço é, via de regra, um dos obstáculos mais comuns encontrados por qualquer vendedor. 0 preço baixo ajuda a vender, mas, raramente o preço é o fator decisivo. Pesquisas realizadas demonstraram que os fatores confiança, qualidade, diversidade de opções e atendimento ficaram sempre a frente do famoso preço baixo. 0 bom preço atrai o consumidor, mas é o atendimento de qualidade que fideliza o cliente. Cliente encantado é o verdadeiro mantenedor de qualquer empresa, o diferencial competitivo num mercado globalizado, que oferece produtos equivalentes a preços similares é determinante para o sucesso da empresa.

Com isso, a recomendação é não vender preço e sim valor. A diferença entre uma loja e outra está no mix, nas facilidades, na rapidez com que se resolvem os problemas do cliente, na política adequada de preços e nos esquemas promocionais. 0 comércio varejista não pode mais trabalhar focado em preço, é preciso investir em atendimento e serviço. Estes diferenciais são atributos que fazem a diferença e conquista o consumidor.

A Rede Casas Bahia é um exemplo de sucesso no atendimento às classes de renda mais baixa. Ela vende os mesmos produtos que seus concorrentes, mas vende muito mais. Por meio de critério fácil e rápido possibilita que todos adquiram aquilo que lhe satisfaz. Entrar na loja e receber um simpático cumprimento talvez seja a principal arma usada para dizer ao cliente: "Estamos à sua disposição". 0 pioneiro nessa prática foi a gigante mundial Wal-Mart, que colocou simpáticas atendentes, distribuindo folhetos promocionais e cumprimentando com um sorriso a todos os clientes logo na entrada da loja. Tornar a entrada da loja um momento diferente é essencial, o auxílio ao cliente deve começar na frente da empresa. Os funcionários devem estar com os sentidos apurados para perceber que o cliente acaba de entrar na loja e que este, por sua vez, está precisando de ajuda.

Não obstante, todo este processo não é tão simples quanto parece, pois, para que isso funcione, é preciso que haja um padrão de comunicação interna que permita a rápida ação dos 
colaboradores. Nesse sentido, todos os colaboradores devem receber treinamentos apropriados para que conheçam bem a empresa e seus produtos e assim, possam informar com presteza aos clientes quando solicitados e, principalmente, saber abordar o cliente com gentileza, usando uma linguagem adequada, de modo que ele se sinta a vontade para aceitar a ajuda.

As organizações têm procurado aprender técnicas, métodos e sistemas que permitam aumentar sua competitividade através do fator diferencial da qualidade do atendimento. A visão estratégica do moderno modelo de gestão é a busca da satisfação do cliente, embora outra vertente afirme que é a fidelização dos clientes o maior objetivo. E isso depende da participação de todos os elementos da organização dentro de um processo de aprimoramento contínuo como recurso estratégico fundamental. 0 papel do vendedor esta mudando. Numa sociedade baseada na informação e numa concorrência cada vez mais acirrada, o vendedor que apenas tira pedido está em extinção. Hoje em dia, o vendedor deve conhecer o seu produto, saber localizar novos clientes e entender o que ele deseja.

É importante contratar bons funcionários e saber delegar funções, pois, quem tem uma boa equipe não sofre de estresse. 0 espírito de equipe se reflete diariamente sobre os negócios. Funcionário bem tratado pela empresa trata bem o cliente. Os problemas decorrentes do relacionamento diário e da rotina do trabalho podem ser antecipados e evitados. No processo de satisfação do cliente é fundamental ouvir para entender, pois, a partir deste princípio é que se percebe o que o cliente está sentindo, querendo, pensando, cada cliente é um "caso". Sua sensibilidade diante de suas reações podem ser utilizadas para o fechamento de uma venda, atendendo as suas expectativas e, principalmente, a do cliente. Não adianta que o conhecimento teórico das informações fique apenas no papel, nas reuniões periódicas ou nos treinamentos de capacitação se, na prática, não for aplicado no cotidiano da empresa, pois, além do conhecimento, da experiência e da vontade, o fator humano como agente de flexibilidade no processo de intuição é o que importa para o processo nas vendas.

Porém, todo este processo requer um esforço permanente, apoiado em uma profunda mudança de atitudes e comportamentos e em fatores essencialmente humanos tais como comunicação, auto-disciplina, auto-estima, respeito e senso comum.

\section{O ENVOLVIMENTO ENTRE A MARCA E O CONSUMIDOR}

Uma marca não pode desenvolver um relacionamento profundo sem uma compreensão rica e criteriosa do cliente. É preciso encontrar os pontos de ressonância do cliente, ou seja, aquela parte de sua vida que representa um envolvimento e comprometimento significativos e expressa quem eles são, seu jeito e conhecimento sobre si mesmo. Acrescentamos ainda que o segredo consiste em aprender com os clientes como indivíduos em vez de aprender sobre os clientes como grupos. E, para isso é necessário observar os valores e as crenças dos clientes, suas atividades, interesses e bens (em outras palavras, o que eles são, fazem e têm).

A importância da marca é vista como fonte de satisfação na mente das pessoas. A marca é fundamental para a estratégia geral de produto, os consumidores precisam relacionar suas experiências de consumo a algum sinal tangível e visível. 0 consumidor terá uma informação facilmente identificável à qual recorre para o processo decisório de compra. 0 consumidor terá maior segurança na escolha ao adquirir um produto.

A marca é importante por mostrar o esforço e concepção de um produto e sua comercialização, com o objetivo de dar-lhe um lugar determinado na mente do consumidor, 
fornecendo segurança na escolha. Deve-se levar em conta o fato de que a imagem mantida pelos consumidores sobre as marcas pode comportar elementos visuais que transcrevem as palavras de nomes fortes para os produtos.

A marca fornece segurança na escolha do produto. 0 cliente avalia a confiabilidade e a honestidade e ao se sentir seguro tanto em valor como em produto, acaba optando por marcas famosas, confirmando assim, que a marca cria associações positivas que garantem ao produto posições firmes no mercado consumidor, resistindo os avanços da concorrência.

\section{PROMOÇÃO DE VENDAS}

A Promoção de Vendas é uma pressão de marketing feita dentro e fora da mídia e aplicada durante um período pré-determinado e limitado ao âmbito do consumidor ou do varejista ou do atacadista, a fim de estimular a experiência com um produto e aumentar a demanda ou a disponibilidade.

Para KOTLER (2000, p.720), as empresas utilizam ferramentas de promoção de vendas para atrair uma resposta mais forte e rápida do comprador, apresentando os seguintes benefícios:

1 - Comunicação: chamam a atenção e geralmente oferecem informações que podem levar o consumidor ao produto.

2 - Incentivo: incorporam algum tipo de concessão, estímulo ou contribuição, que são valiosas para o consumidor.

3 - Convite: constituem um convite especial para a transação imediatamente.

A promoção de vendas envolve uma série diversificada de instrumentos que podem ser agrupados, segundo o campo de atuação, em três áreas:

1 - Promoção dirigida ao consumidor: amostras, cupons, ofertas de devolução de dinheiro, descontos, prêmios, concursos, selos comerciais e demonstrações.

2 - Promoção dirigida aos lojistas: abatimentos na compra, mercadorias gratuitas, descontos nos produtos e concurso de vendas para revendedores.

3 - Promoção dirigida aos Vendedores: prêmios, concursos e competições de vendas.

Não obstante, este processo deve começar na definição de um público-alvo, tais como: os possíveis compradores dos produtos da empresa, os usuários atuais, as pessoas que decidem ou influenciam, os indivíduos, os grupos, os públicos específicos ou o público em geral. 0 público-alvo exerce uma influência fundamental nas decisões do comunicador sobre o que, como, quando, onde e para quem dizer.

A seleção do mercado-alvo é o primeiro passo crítico no sentido da comunicação de marketing eficaz e eficiente. Ela permite que os comunicadores definam com precisão o público potencial do produto e transmitam mensagens para esse grupo. Tal conduta traz benefícios, evitando desperdício de recursos promocionais valiosos com os consumidores fora do mercado-alvo. 0 público-alvo é o grupo de pessoas que a mensagem de marketing pretende atingir. A comunicação integrada de marketing deve ser desenvolvida para agregar valor para um público-alvo em especial, como um segmento de mercado específico, clientes potenciais ou parceiros de canal. 


\section{O ESTUDO DO CASO ZONA SUL}

\section{MUDANÇAS NO VAREJO E NA REDE ZONA SUL}

0 varejo brasileiro encontra-se em uma fase de importantes mudanças, que estão culminando em processos de reestruturação interna de empresas, assim como do setor como um todo. Além disso, em função de um processo de maior organização das atividades e de informatização, o varejo vem adotando um novo padrão de relacionamento com fornecedores e passou a deter, de forma ampla, informações sobre o comportamento dos diferentes consumidores.

A disponibilidade destes dados, em conjunto com a concentração do setor, aumenta o poder do varejo em relação aos produtores, acompanhando a tendência mundial de transferência do poder na cadeia produtiva, da indústria para o varejo.

\section{A REESTRUTURAÇÃO DA REDE}

Observa-se a reestruturação da rede Zona Sul de várias formas, tendo por objetivo ajustar e se adequar ao ambiente de competição mais intensa, decorrente, principalmente, das conhecidas transformações da economia brasileira operadas no início da década de 90. Segundo o Diretor Comercial do Supermercado Zona Sul, Jaime Xavier, podemos destacar algumas delas:

1 - fechamento de lojas menos rentáveis ou não lucrativas e reformas de lojas existentes;

2 - adequação do perfil de endividamento/renegociação de dívidas;

3 - profissionalização das administrações, de tradicional característica familiar;

4 - busca por maior capitalização através de novos negócios dentro de seu próprio negócio;

5 - elevação do grau de utilização de automação comercial e de recursos de informática;

6 - aperfeiçoamento do conhecimento do cliente final;

7 - retomada dos instrumentos de planejamento e aperfeiçoamento de instrumentos de aferição de custos e controles.

Particularmente relevantes foram as mudanças introduzidas na economia após a implementação do Plano Real. Para as empresas que já estavam se reestruturando, a estabilidade da moeda representou uma potencialização do faturamento. Destacaram-se, ainda, aquelas empresas que souberam detectar as necessidades de implementar mudanças no posicionamento estratégico ou que resolveram investir em métodos e processos destinados a elevar a eficiência operacional e a aumentar a competitividade como um todo, decidindo e implantando tais medidas ainda em meio a crises financeiras ou a períodos recessivos da economia brasileira recente.

A rede Zona Sul soube se adequar bem a este novo ambiente. Para as empresas que já enfrentavam em dificuldades em razão de inadequações operacionais ou administrativas, 0 concomitante aumento da concorrência expôs as dificuldades em mudar rapidamente, principalmente na redefinição do foco de atuação e na adequação ao novo quadro de competição. Algumas passaram a apresentar desequilíbrios financeiros, requerendo-se a falência e a concordata de tradicionais empresas, como ocorreu com as Casas Pernambucanas e com a Mesbla. 
As empresas mais atingidas negativamente foram as tradicionais lojas de departamentos, que passaram a apresentar certa perda de identidade em virtude das freqüentes tentativas de mudanças e das indefinições do foco de atuação. As medidas adotadas para a correção de rumo, nestes casos, têm sido, a troca de controle acionário e a reestruturação das dívidas, alterando-se, nesse processo, os conceitos operacionais e o posicionamento mercadológico dessas empresas.

A rede Zona Sul, já ajustada, prepara-se para planos de crescimento e esta expansão tem se dado pela busca de alternativas agregando outros serviços dentro de sua própria estrutura de mercado. Sua reestruturação também vem sendo motivada pelas investidas de grandes varejistas mundiais, principalmente europeus, para os quais existe uma certa saturação em seus mercados de origem. Assim, estes grupos têm partido para operar em outros países, atraídos pelo potencial de crescimento das economias emergentes.

De um modo geral, têm sido aproveitados os modelos das empresas líderes para elevar a eficiência e, para as empresas entrantes, tem ocorrido um aprendizado das dificuldades em se transpor e implementar alguns modelos fechados para diferentes culturas e preferências de mercado, impondo a necessidade de certos ajustes.

Atualmente, prossegue o movimento de reestruturação do setor, em virtude da continuação dos processos abordados. Porém, deve-se ressaltar que as medidas de restrição à demanda que foram adotadas, tais como a elevação da taxa de juros e o aumento da inadimplência, afetam as empresas varejistas significativamente, mesmo que de forma diferenciada, e obrigam o permanente ajuste estratégico do setor.

\section{MUDANÇAS E REESTRUTURAÇÕES INTERNAS}

Os aspectos mencionados, o crescimento da concorrência e as alterações de comportamento e hábitos dos consumidores têm sido fundamentais na promoção das significativas mudanças da rede Zona Sul. A concorrência, crescente entre lojas de mesmo formato e entre diferentes tipos de lojas, tem levado a rede à necessidade de implantar programas de redução de custos, de racionalização das operações e de diferenciação de serviços para atrair mais consumidores.

Conforme foi explicado por Jaime Xavier, as modificações observadas abrangem, portanto, a busca de maior eficiência operacional e de melhorias na gestão da rede, de forma a capacitá-la a obter vantagens comparativas mais sustentáveis cada vez mais concentradas na estrutura de custos, na qualidade, no atendimento e nos serviços oferecidos, do que em sortimento e preços, que tendem a ser muito parecidos com a concorrência. Estas vantagens estão baseadas principalmente em:

a) definição correta do mix de vendas observando as classes econômicas predominantes em suas lojas, elemento vital para lucratividade da empresa;

b) agregação de serviços de forma perceptível ao consumidor, oferecendo mais por menos;

c) informatização como elemento cada vez mais importante e no suporte à sua atividade de distribuição;

d) emprego de novos sistemas, ferramentas e técnicas, como gestão de estoques, gerência por categoria, Electronic Data Interchange (EDI), benchmarking etc.; 
e) conceito de parceria e de aproveitamento de sinergias entre atividades dos diversos agentes na cadeia de valor: produtores, distribuidores, varejistas e clientes finais.

Este último quesito merece destaque, pois grande parte do tempo destinado pelo Diretor Comercial da rede está direcionado para a busca e sedimentação de novos fornecedores que possam desenvolver serviços e produtos exclusivos para a rede.

O EDI (Eletronic Data Interchange) é, por exemplo, uma das formas de integração entre a rede e seus fornecedores, substituindo documentos comerciais como pedidos de compra, faturas, conhecimento de embarque, avisos de recebimento etc.

Um outro aspecto relevante é a mudança dos hábitos dos consumidores brasileiros, relacionada, por exemplo, à preocupação quanto a produtos mais saudáveis, maior participação da alimentação fora de casa, aumento da compra de produtos semiprontos, entre outros. A maior segmentação dos tipos de consumidores e famílias também é outro ponto a ser considerado, tendo em vista a criação de produtos voltados para atender a esta diversidade.

Estas são alterações importantes, pois o foco do negócio, portanto, volta-se para o atendimento dos desejos e necessidades dos clientes, aspecto que a rede Zona Sul tem como meta prioritária. Conceitos tais como a fidelização dos clientes e do valor atribuído pelos consumidores à relação custo/benefício da compra são explorados pelo Zona Sul.

Com relação ainda às reestruturações internas, deve-se destacar o papel fundamental da logística, atualmente uma das grandes preocupações da rede e que está também fortemente ligada aos avanços da informatização. Verifica-se o investimento em sua central de distribuição, que é uma questão relacionada à centralização de compras e à maior eficiência do sistema de logística.

\section{OS IMPACTOS NA REDE}

A rede Zona Sul vem adotando medidas para aumentar a eficiência operacional e manter a rentabilidade das vendas, tais como o re-estudo das margens, a redução de custos, a negociação mais forte com os fornecedores e a redefinição do mix de produtos. A evolução é no sentido de adotar a terceirização de atividades não essenciais, com vistas a estabelecer parcerias logísticas com fornecedores e melhorar o planejamento de seus estoques e níveis de compras.

Esta parceria é ainda incipiente e implica modificações de comportamento e de processos de organização, bem como investimentos dos fornecedores em maior ou menor grau, de acordo com o seu porte. Por outro lado, esta evolução também requer da rede uma melhor previsão de demanda e programação de compras, maior transferência de informações quanto aos hábitos dos consumidores e instalações cada vez mais eficientes para descarregamento de mercadorias.

No Brasil, o segmento de supermercados é o que vem recebendo os maiores impactos dessas transformações, pois enfrenta uma competitividade cada vez maior, o que leva à necessidade de aumentar a produtividade. Algumas das transformações pelas quais passa a rede são, por exemplo, a maior presença de fornecedores exclusivos e diferenciados, e o aumento da diversidade de comportamento de seus consumidores. 


\section{OS SUPERMERCADOS NO BRASIL}

Há, no Brasil, uma tendência à concentração. Em 2006, verificamos que as 20 maiores empresas de hipermercados e supermercados foram responsáveis por $64 \%$ do faturamento das 300 maiores, enquanto em 2001 esse índice era de 58\%. As duas maiores redes, Carrefour e Pão de Açúcar, responderam por $26 \%$ do faturamento das 300 maiores redes em 2001, enquanto as cinco maiores e as 10 maiores foram responsáveis, respectivamente, por $40 \%$ e $49 \%$ desse faturamento. Uma das causas da reestruturação é a aceleração da internacionalização das empresas de hipermercados e supermercados, em que se conjugou a necessidade de expansão e de escala global com a saturação dos mercados de origem das grandes redes internacionais.

O Brasil apresenta uma grande atração para a instalação de novas redes, pois possui um grande mercado, possibilidade de incorporação de novos consumidores, sucesso na atuação de redes internacionais já presentes no país, baixo poder de competitividade do setor instalado e legislação sem restrição à entrada de grandes varejistas. A participação do capital estrangeiro, principalmente europeu, tem aumentado com a entrada das grandes redes internacionais no Brasil.

\section{A ESTRATÉGIA DO SUPERMERCADO ZONA SUL}

A estratégia da rede Zona Sul esta fundamentada na manutenção de sua posição no mercado, colocando sua marca cada vez mais focada na inovação e no atendimento exclusivo. Sua expansão busca a consolidação de sua posição nos mercado, além de melhor negociação com os fornecedores. Atualmente, a empresa está se expandindo através da construção de novas lojas com serviços diferenciados e em locais nobres.

Com o crescimento da rede e da concorrência, torna-se elemento fundamental da estratégia a operação logística, que está associada, principalmente, à exploração de recursos de tecnologia de informação e comunicação.

Atualmente, em 2009, a rede centraliza sua distribuição, pois seus pontos de abastecimento merecem um cuidado muito grande. São lojas pequenas e quase sempre com horários determinados pelo poder público para a operação de descarregamento. Mesmo assim, a operação se faz de forma exemplar e sua eficácia cresce a cada ano.

No que diz respeito ao relacionamento com os fornecedores, as políticas de compras, as novas formas de trabalho e de organização e a informatização da rede estão levando a um novo comportamento frente aos fornecedores. Dentre as mudanças que merecem destaque, está a realização de parcerias entre fornecedores e a realização de contratos de fornecimento de longo prazo. Esta parceria abrange a reposição de produtos com funcionários próprios da indústria, o compartilhamento de informações para lançamento de novos produtos ou para promoções, a definição da forma de colocação dos produtos nas lojas, o monitoramento do nível de estoques, a fabricação de produtos exclusivos etc.

Em geral, esse relacionamento ocorre de diferentes formas, que são escolhidas também de acordo com o poder do fornecedor frente ao varejista. Este, ao analisar o fornecedor, avalia o melhor preço, a forma de pagamento e o serviço que ele oferece. Porém, novos fatores vêm sendo crescentemente observados, tais como a pontualidade de entrega, a garantia de qualidade dos produtos e ampliação dos serviços prestados. Estes aspectos estão sendo gradativamente introduzidos e representam, em alguns casos, de acordo com o produto ou o 
fornecedor, uma mudança significativa.

$\mathrm{Na}$ busca de obtenção de ganhos de lucratividade, a rede Zona Sul procura otimizar e diversificar o abastecimento de mercadorias. Entre as formas que a rede dispõe são a importação, a oferta de produtos com marcas exclusivas e o desenvolvimento de fornecedores, conforme destacado inicialmente.

0 gerenciamento de categorias refere-se à distribuição mais eficiente das seções nos hipermercados e supermercados, segundo a preferência do consumidor e a maximização dos resultados das vendas, bem como a disposição dos produtos nas gôndolas, procurando-se entender a racionalidade do consumidor na hora de efetuar suas compras e, assim, atraí-lo. Alguns dos benefícios do gerenciamento de categorias são, entre outros: medir o valor que cada fornecedor tem junto ao consumidor, saber o lucro de cada marca, melhorar a organização e a imagem da loja, atraindo mais consumidores, aumentar as vendas por impulso, por conveniência e complementares e permitir a análise da cadeia de suprimento, prevendo-se a logística necessária e o custo para abastecer. A rede Zona Sul adota este gerenciamento buscando ajuda em seus fornecedores, já que estes possuem um conhecimento mais específico em relação a cada posicionamento.

A rede Zona Sul percebeu que, no meio de tantas variáveis, está havendo uma redução na fidelidade dos consumidores, o que implica a necessidade de aumentar os gastos com propaganda e de prestar maior atenção às expectativas do consumidor. Isso faz com que o segmento comece a despertar para a urgência de realização de pesquisas periódicas junto aos consumidores e de implantação de programas de clientes freqüentes. 0 lançamento de um sistema de fidelização pela rede promoveu a fidelização de clientes e, paralelamente, um acréscimo de $26 \%$ nas vendas.

Conseguir a fidelidade do cliente é o resultado de um grande trabalho voltado para sua satisfação e que envolve não só critérios racionais mas também subjetivos, como, por exemplo, exposição de mercadorias em grandes quantidades, crédito e diferentes formas de pagamento. Os dados gerados pelos terminais de venda permitem conhecer cada cliente da loja e elaborar programas de clientes freqüentes.

Segundo a Gerente de Marketing, Maria Fernanda, a fidelização desenvolvida na rede Zona Sul pode ser seguida como exemplo para outras redes, pois além do cliente ter uma redução nos preços somente pelo fato dele ser cadastrado como cliente rotineiro, serviços tais como a entrega programada com hora marcada, empacotadores, especialistas de vinhos e queijos nas seções, profissionais treinados e qualificados, são diferenciais percebidos e defendidos pelos próprios clientes.

No Brasil já ocorrem iniciativas como o exemplo mencionado, porém não se considera que haja outra empresa com programa consistente de fidelização de clientes semelhante a partir da análise das informações geradas nos pontos de venda.

\section{A MARCA ZONA SUL E SEUS DIFERENCIAIS}

Desde a sua fundação, em 1960, o supermercado Zona Sul vem oferecendo atendimento personalizado, a melhor seleção de produtos nacionais e importados a fim de satisfazer um público exigente e de bom gosto.

Com o passar do tempo, o Zona Sul foi se modernizando e hoje conta com 30 lojas localizadas na Zona Sul da cidade, Barra da Tijuca, Recreio dos Bandeirantes e Angra dos Reis. Contudo, 
não abriu mão da preocupação constante com a qualidade dos produtos e o bem-estar de seus clientes.

Em constante busca pelo aperfeiçoamento, bastou um cliente comentar há 43 anos atrás, que gostaria de receber suas compras em casa, para que o Zona Sul estruturasse o seu serviço de entrega. Assim surgiu o Zona Sul Atende.

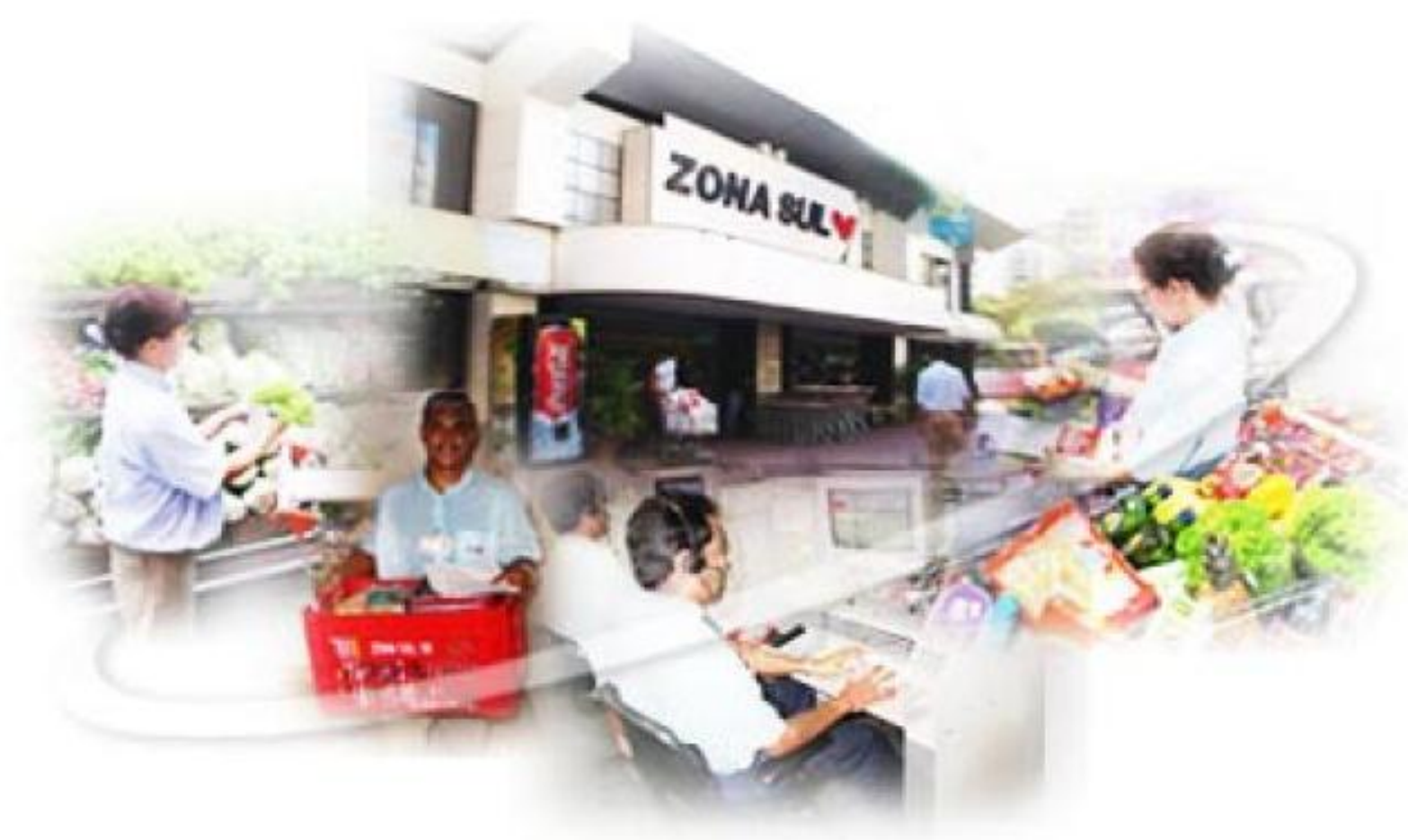

Inicialmente, as compras eram feitas por telefone e fax, e hoje, através da Internet, dispomos de um web-site rápido e moderno para facilitar ainda mais suas compras. Seus colaboradores são treinados para fazer suas compras com o mesmo cuidado e atenção que o cliente tem quando vai ao supermercado pessoalmente. Basta escolher os produtos e marcas que são separadas e entregues com toda a segurança.

Para o marketing do Zona Sul, o fortalecimento de sua marca se faz por meio do direcionamento para o exclusivo e inovador. Hoje, nos locais onde existe uma loja do Zona Sul, existe também o reconhecimento de excelência no atendimento, produtos únicos, variedades de importados e conforto, mesmo tendo lojas pequenas.

Para se ter uma idéia do grau de inovação que a rede possui, já existem serviços de café da manhã em algumas lojas para clientes que não desejam ter trabalho em casa. Você se serve com uma grande variedade de matinais, pesa e desfruta de um lugar agradável.

Outro serviço que merece destaque são as famosas pizzarias dentro das lojas maiores. 0 consumidor já reconhece e até compara a qualidade da pizza com pizzarias famosas. A higiene e o bom atendimento são quesitos novamente observados com entusiasmo.

Se um cliente desejar convidar alguns amigos para uma reunião e não conhecer nada de queijos e vinhos, para a rede Zona Sul isto não é problema. Todas as lojas possuem 
especialistas que poderão seguramente orientar as adequadas combinações.

Outros serviços com igual qualidade merecem destaque, como a Spaghetteria, o Sushi bar e a peixaria. Nesta última, o cliente não precisa sequer escolher o peixe, pois todos os que foram colocados em exposição também foram previamente selecionados.

Os números do Zona Sul falam por si e comprovam que o caminho seguido está em conformidade com a expectativa de consumo das classes de renda dos cliente onde estão localizadas as suas lojas.

Verifica-se também um expressivo crescimento do serviço de compra pela internet, fato que demonstra a excelência dos investimentos em logística e Tecnologia de Informação e Comunicação.

\section{CONCLUSÕES}

O comércio varejista encontra-se em uma fase de importantes mudanças, que estão culminando em processos de reestruturação, com maior participação de empresas estrangeiras e maior peso dos grandes grupos. As mudanças que vêm ocorrendo e o processo de reestruturação já atingem os principais setores do varejo, embora o segmento de supermercados e hipermercados seja o mais avançado.

A adoção de práticas e de "organização da produção" mais modernas visa garantir espaço em um novo cenário em que a concorrência enfatiza a importância da gestão das empresas e sua capacidade em traçar estratégias, assim como a busca de eficiência da cadeia varejofornecedor.

Processos de informatização, formas modernas de organização do processo e políticas de compras são alguns dos aspectos relevantes que estão levando, por exemplo, a um novo padrão de relacionamento com fornecedores, maior enfoque na logística, gestão e treinamento de recursos humanos.

A rede Zona Sul vem adotando medidas para aumentar a eficiência operacional e manter a rentabilidade das vendas e têm evoluído no sentido de estabelecer parcerias logísticas com seus fornecedores, além de planejar melhor seus estoques e níveis de compras.

A implementação destas mudanças vem ocorrendo de forma diversa, porém são aspectos que modificam o perfil do setor varejista do país. Com este estudo, é possível concluir que é possível crescer mesmo não tendo um diferencial onde todos os seus concorrentes se preocupam: o fator preço.

Para o ambiente do marketing e seus gestores, este conjunto de estudos pode abrir uma outra percepção de que podemos gerir de forma diferente, mais direcionada, comunicando e oferecendo serviços e procurando agregar estes serviços em benefício próprio da organização.

A força de uma marca não significa amplitude total de seu reconhecimento. Marca forte para este estudo significa força e reconhecimento direcionados. E possível então responder a indagação: as estratégias mercadológicas usadas pela rede de supermercados Zona Sul para consolidar sua marca no mercado varejista e seus desafios na competitiva cidade do Rio de Janeiro são efetivas?

Podemos responder que sim. Seus resultados financeiros são crescentes ano após ano, seus 
serviços diferenciados são cada vez mais utilizados e admirados e sua expansão permanecerá, conforme afirma o Diretor Comercial da rede.

Com esta afirmação, a suposição argüida no início do estudo é confirmada já que a referida rede de supermercados conseguiu se destacar de grandes concorrentes regionais e até nacionais, desenvolvendo um grupo de serviços atrelado ao ambiente frio dos corredores de um supermercado. Sua marca é reconhecida e prestigiada.

\section{REFERÊNCIAS BIBLIOGRÁFICAS}

AAKER, David A, JOACHIMSTHALER, Erich. Como construir marcas líderes. Porto Alegre: Bookman, 2007.

AAKER, David A. Marcas: Brand Equity. Gerenciando o Valor da Marca. Tradução André Andrade. São Paulo: Negócio Editora, 1998.

Criando e Administrando Marcas de Sucesso . São Paulo: Futura 1996.

ABRAS, Cinquenta Anos de Supermercados no Brasil, fundação Abras.São Paulo, 2001.

KOTLER, Philip. Administração de Marketing: Análise, Planejamento, Implementação e Controle. Tradução Ailton Bonfim Brandão. São Paulo: Atlas, 1991.

Marketing para o Século XXI: Como Criar, Conquistar e Dominar Mercados. tradução Bazán Tecnologia e Lingüística São Paulo: Futura, 1999.

MARTINS, José Roberto. Branding: Um Manual para Você Criar, Avaliar e Gerenciar Marcas. São Paulo: Negócio Editora , 2000.

Grandes Marcas. Grandes Negócios. Como as Pequenas e Médias Empresas Devem Criar e Gerenciar uma Marca Vencedora. São Paulo: Negócio Editora, 1997.

MARTINS, Carlos www.usp.br/pesquisas/estudodecaso acessado em 19/07/08.

MCKENNA, Regis. Marketing de Relacionamento. Rio de Janeiro: Campus, 1997.

SUPER HIPER, Panorama 2007, Análises e Estatísticas, Associação Brasileira de Supermercados, São Paulo 2007

VERGARA, Silvia Costant. Projetos e relatórios de Pesquisas em administração. São Paulo: Atlas 1997. 